Quim. Nova, Vol. 34, No. 2, 206-212, 2011

\title{
DESENVOLVIMENTO DE MÉTODOS DE ANÁLISE POR CLAE-UV PARA OS ANTIMICROBIANOS TETRACICLINA, SULFAMETOXAZOL E TRIMETOPRIMA UTILIZANDO MATERIAIS À BASE DE SÍLICA COMO SISTEMAS DE PRÉ-CONCENTRAÇÃO
}

\author{
Rosana Cristina Ribeiro Pedroso, Maria do Carmo Ruaro Peralba, João Henrique Zimnoch dos Santos e Tânia Mara Pizzolato* \\ Instituto de Química, Universidade Federal do Rio Grande do Sul, Av. Bento Gonçalves, 9500, 91501-970 Porto Alegre - RS, Brasil \\ Pedro Eduardo Fröehlich
}

Faculdade de Farmácia, Universidade Federal do Rio Grande do Sul, Av. Ipiranga, 2752, 90610-000 Porto Alegre - RS, Brasil

Recebido em 8/1/10; aceito em 1/9/10; publicado na web em 7/1/11

\begin{abstract}
DEVELOPMENT OF ANALYTICAL METHODS FOR HPLC-UV TO THE ANTIMICROBIANS TETRACYCLINE, SULFAMETHOXAZOLE AND TRIMETHOPRIM USING ZIRCONOCENE-BASED SILICA AS PRE-CONCENTRATION/ EXTRACTION SYSTEMS. This paper evaluates the adsorption capacity of zirconocene-based silica materials in the preconcentration of antimicrobians (tetracycline, sulfamethoxazole and trimethoprim) in aqueous medium. These materials were prepared by grafting the zirconocene onto silicas pre-treated at different temperatures. The retention capacity of these materials was evaluated by off line SPE and HPLC-UV and the proposed methodology was validated in ultrapure, tap and river water. The recovery for tetracycline was $72 \%$ (in the solid phase A) and, for sulfamethoxazole and trimethoprim was 68 and $95 \%$ in the commercial C18, respectively. The target antimicrobians were not detected in the Arroio Dilúvio (Porto Alegre - RS).
\end{abstract}

Keywords: antimicrobians; silica-based material; solid-phase extraction.

\section{INTRODUÇÃO}

Nos últimos anos uma grande variedade de resíduos de fármacos têm sido detectados no meio ambiente, em especial em água potável, ${ }^{1-3}$ águas naturais ${ }^{4}$ e efluentes domésticos. ${ }^{5} \mathrm{~A}$ ocorrência desses compostos, designados por contaminantes emergentes, tem despertado preocupação pois eles são compostos bioativos, ou seja, são sintetizados para uma intenção específica nos seres vivos. Por essa razão os fármacos podem também ter efeitos tóxicos nos organismos aquáticos. ${ }^{6-8} \mathrm{~A}$ principal entrada desses produtos no meio ambiente resulta de sua utilização na medicina humana e veterinária, uma vez que após a administração são parcialmente metabolizados e excretados. Isto é decorrente do fato de que os fármacos são desenvolvidos para serem persistentes, mantendo suas propriedades químicas o bastante para servir ao propósito terapêutico. ${ }^{8,9}$

Um dos grupos de fármacos que merece especial atenção é o dos antimicrobianos. Eles têm sido amplamente investigados no meio ambiente nos últimos anos, principalmente devido ao seu potencial quanto ao desenvolvimento de bactérias. ${ }^{9-20}$ Dentre os antimicrobianos, a tetraciclina (TC), que é produzida a partir de cepas de micro-organismos ou como produto semissintético, o sulfametoxazol (SMX) e a trimetoprima (TM), que são antimicrobianos sintéticos, representam três fármacos largamente usados na medicina humana e veterinária. ${ }^{13-17,21}$

Para detecção de fármacos no meio ambiente aquático, faz-se necessário o desenvolvimento de métodos sensíveis capazes de detectar as baixas concentrações em que estes compostos poderão estar presentes. Além disso, a complexidade da matriz ambiental envolve um grande número de compostos que podem interferir nas análises, dificultando esta etapa quando as amostras não são previamente tratadas. As técnicas de extração e/ou pré-concentração auxiliam significativamente a análise dos componentes de interesse em matrizes complexas, principalmente em baixas concentrações. ${ }^{22}$ A extração em fase sólida (EFS) tem sido um dos procedimentos mais empregados para extração e/ou pré-concentração de analitos em nível de traços em matrizes complexas ou não. A EFS emprega adsorventes empacotados em cartuchos, pelos quais a amostra é percolada; os analitos de interesse são pré-concentrados e, posteriormente, eluídos para serem analisados. Os mecanismos de retenção envolvidos são idênticos àqueles da cromatografia líquida em coluna. Atualmente, um grande número de adsorventes está disponível comercialmente. ${ }^{21}$ No entanto, a obtenção de adsorventes produzidos em laboratórios também é uma alternativa promissora. ${ }^{23}$ Materiais alternativos como grafite, crisotila, entre outros, já foram investigados na literatura.

Em trabalho anterior, foram desenvolvidas fases sólidas à base de sílica quimicamente modificadas com o intuito de préconcentrar poluentes orgânicos presentes em matrizes ambientais, em substituição às fases sólidas comerciais. Fases sólidas funcionalizadas com diclorobis (ciclopentadienil) zircônio (IV) pelo método grafting $^{23}$ foram sintetizadas e avaliadas na pré-concentração de diversos analitos polares. ${ }^{24}$ Em extensão a esse trabalho, estas fases sólidas foram avaliadas quanto ao seu desempenho na préconcentração de tetraciclina, sulfametoxazol e trimetoprima, em nível de traços, em meio aquoso. Para as fases sólidas que apresentaram melhores resultados na etapa de pré-concentração, a metodologia analítica para TC e a metodologia analítica para SM e TM foram validadas. Cabe salientar que a presente sílica funcionalizada busca combinar a presença de sítios ácidos de Lewis (existente no átomo de Zr) com sítios básicos de Lewis introduzidos através do anel ciclopentadienila presente na esfera de coordenação desse complexo metálico. 


\section{PARTE EXPERIMENTAL}

\section{Reagentes e materiais}

Padrões de cloridrato de tetraciclina, com teor de 98,6\% (adquirido da Importadora Química Delawere Ltda, Porto Alegre, RS, Brasil), trimetoprima, com teor de 99,36\%, (adquirido do Laboratório Farmacêutico do RS, Porto Alegre, Brasil) e sulfametoxazol com teor de 100,5\% (adquirido de Deg Importação de Produtos Químicos Ltda, São Paulo, SP, Brasil) foram utilizados como substâncias químicas de referência. Os reagentes N,N-dimetilformamida, ácido oxálico, oxalato de amônio (Merck), trietilamina, ácido acético glacial (Vetec) e fosfato de amônio dibásico (Synth), todos com grau de pureza para análise; metanol e acetonitrila (Omnisolv e/ou Mallinckodt) com grau de pureza para análise de resíduo e água ultrapura (Milli-Q) com resistividade controlada em 18,2 $\mathrm{M} \Omega \mathrm{cm}$, foram empregados como solventes.

\section{Fases sólidas à base de sílica quimicamente modificadas}

As fases sólidas, à base de sílica quimicamente modificada, foram preparadas pelo método grafting, ${ }^{23}$ em que os grupos $\mathrm{OH}$ da sílica foram substituídos por ciclopentadienil zircônio. A diferença entre estes adsorventes está na temperatura de ativação da sílica $(110,200$ e $450{ }^{\circ} \mathrm{C}$ ) que por sua vez afeta os grupos silanois residuais, potenciais sítios de reação e fixação dos metalocenos empregados. O procedimento completo para a síntese e caracterização deste material está descrito alhures. ${ }^{25,26}$ As principais características destes materiais, bem como da sílica comercial utilizada, estão relacionadas na Tabela 1.

Tabela 1. Características físico-químicas dos materiais à base de sílica utilizadas no estudo de retenção dos antimicrobianos

\begin{tabular}{|c|c|c|c|c|}
\hline $\begin{array}{l}\text { Material à base } \\
\text { de sílica }\end{array}$ & $\begin{array}{l}\mathrm{T} \text { de ativação } \\
\text { da sílica }\left({ }^{\circ} \mathrm{C}\right)\end{array}$ & $\begin{array}{c}\text { Teor de } \\
\text { carbono }(\%)\end{array}$ & $\begin{array}{c}\text { Diâmetro médio } \\
\text { de partícula } \\
(\mu \mathrm{m})\end{array}$ & $\begin{array}{c}\text { Área } \\
\text { específica } \\
\left(\mathrm{m}^{2} \mathrm{~g}^{-1}\right)\end{array}$ \\
\hline Sílica A & 110 & 27,4 & 50 & 296 \\
\hline Sílica B & 200 & 20,4 & 50 & 292 \\
\hline Sílica C & 450 & 18,9 & 50 & 290 \\
\hline $\begin{array}{l}\text { C18 Waters } \\
\text { Sep-Pak }\end{array}$ & - & 12 & $55-105$ & n.d. \\
\hline $\begin{array}{l}\mathrm{LC}-18^{\mathrm{TM}} \\
\text { Supelco }\end{array}$ & - & $\sim 11,5$ & 45 & 475 \\
\hline
\end{tabular}

nd: não determinado.

\section{Preparo das soluções padrão de estoque e de trabalho}

A solução padrão estoque de cloridrato de tetraciclina (TC) foi preparada na concentração de $100 \mathrm{mg} \mathrm{L}^{-1}$ no solvente de diluição (mistura de $680 \mathrm{~mL}$ de oxalato de amônio $0,1 \mathrm{~mol} \mathrm{~L}^{-1}$ e $270 \mathrm{~mL}$ de $\mathrm{N}, \mathrm{N}$-dimetilformamida) e mantida ao abrigo da luz. As soluções padrão de trabalho de TC foram preparadas diariamente pela diluição sucessiva da solução padrão estoque nas concentrações de 10, 25, 50, 100, 200 e $1000 \mu \mathrm{g} \mathrm{L}^{-1}$ no solvente de diluição e mantidas ao abrigo da luz. As soluções utilizadas nos estudos de adsorção/dessorção foram preparadas diariamente na concentração de $10 \mu \mathrm{g} \mathrm{L}^{-1} \mathrm{em}$ água ultrapura de sistema Milli-Q.

A solução padrão estoque mista de sulfametoxazol (SMX) e trimetoprima (TM) foi preparada na concentração de $100 \mathrm{mg} \mathrm{L}^{-1} \mathrm{em}$ metanol e mantida ao abrigo da luz. As soluções padrão de trabalho de SMX e TM, nas concentrações de 5, 10, 25, 50, 100, e $1000 \mu \mathrm{g}$ $\mathrm{L}^{-1}$ foram preparadas diariamente na fase móvel $\left(\mathrm{H}_{2} \mathrm{O}\right.$ :ACN:TEA
799:200:1 (v/v) pH: 5,9 \pm 0,1 corrigido com ácido acético), pela diluição sucessiva da solução padrão estoque. As soluções utilizadas no estudo de adsorção/dessorção foram preparadas diariamente na concentração de $10 \mu \mathrm{g} \mathrm{L}^{-1}$ em água ultrapura de sistema Milli-Q, com uma solubilização inicial em metanol (máximo $1 \mathrm{~mL}$ ). Todas as soluções preparadas foram mantidas ao abrigo da luz.

\section{Condições cromatográficas}

As análises cromatográficas foram realizadas por cromatografia líquida de alta eficiência com detector de Ultravioleta (CLAE-UV) em equipamento Shimadzu LC-10A, equipado com detector de UV-Vis SPD-10A. As análises de TC foram realizadas em coluna cromatográfica Shimadzu Shim-pack CLC-C8 (M) $(150 \mathrm{~mm} \times 4,6$ $\mathrm{mm})(5 \mu \mathrm{m})$ endcapped e pré-coluna Shimadzu GC8 $(30 \mathrm{~mm} \times 4,6$ $\mathrm{mm})(10 \mu \mathrm{m})$ endcapped. O comprimento de onda ajustado para as medidas do detector foi de $280 \mathrm{~nm}$. A fase móvel foi oxalato de amônio $0,1 \mathrm{~mol} \mathrm{~L}{ }^{-1}$ :DMF:fosfato de amônio dibásico $0,2 \mathrm{~mol} \mathrm{~L}^{-1}$ na proporção de 680:270:50 (v/v) (pH: entre 7,6 a 7,7), conforme recomendação da USP. ${ }^{27}$

As análises de SMX e TM foram realizadas em uma coluna cromatográfica Shimadzu Shim-pack CLCODS (M) $(150 \mathrm{~mm} \times 4,6 \mathrm{~mm})$ (5 $\mu \mathrm{m})$ endcapped e pré-coluna Shimadzu GODS (30 $\mathrm{mm} \times$ 4,6 mm) $(10 \mu \mathrm{m})$ endcapped. O comprimento de onda ajustado para as medidas do detector foi de $254 \mathrm{~nm}$. A fase móvel utilizada foi $\mathrm{H}_{2} \mathrm{O}$ :ACN:TEA na proporção de 799:200:1 (v/v) (pH: 5,9 \pm 0,1 corrigido com ácido acético), conforme recomendação da USP. ${ }^{27}$

Antes das análises cromatográficas, as fases móveis foram filtradas com membrana de nylon 0,45 $\mu \mathrm{m}$ (Millipore) e desgaseificadas com gás hélio $(99,995 \%)$. A vazão das fases móveis foi de $1 \mathrm{~mL} \mathrm{~min}^{-1}$ em modo isocrático e volume de injeção de $20 \mu \mathrm{L}$. Todas as medidas foram realizadas a temperatura ambiente $\left(25^{\circ} \mathrm{C}\right)$.

Os ajustes de $\mathrm{pH}$ foram realizados em $\mathrm{pHmetro}$ Digimed, modelo DM-20 com termocompensador Digimed, modelo DMF-N1.

\section{Amostras}

As amostras de água potável foram coletadas diretamente da torneira do laboratório. As amostras de água de rio foram coletadas no Arroio Dilúvio (Porto Alegre-RS) em dois pontos: antes e após o recebimento de descargas de efluentes domésticos e hospitalares. As amostras coletadas antes do recebimento das descargas de efluentes correspondem a uma área de coordenadas de $30^{\circ} 04^{\prime} 09.12^{\prime \prime} \mathrm{S}, 51^{\circ} 08^{\prime} 26.54$ ” O, elev 180 pés e altitude do ponto de visão 596 pés, e as amostras coletadas após o recebimento das descargas, numa área com coordenadas de $30^{\circ} 02^{\prime}$ $51.64^{\prime \prime} \mathrm{S}, 51^{\circ} 12$ ’ 49.98” O, elev 31 pés e altitude do ponto de visão 364 pés. As amostras foram coletadas em frasco de vidro âmbar previamente descontaminados, transportadas em gelo até o laboratório imediatamente após a coleta. As amostras foram filtradas em filtro de membrana de 0,45 $\mu \mathrm{m}$ e mantidas a $4^{\circ} \mathrm{C}$ em frasco de vidro âmbar totalmente preenchido, em posição vertical, até o momento da análise, que não foi superior a 2 dias para minimizar os efeitos da degradação microbiana. ${ }^{13}$

\section{Estudo de adsorção/dessorção das fases sólidas frente à tetraciclina, ao sulfametoxazol e à trimetoprima}

Os estudos de adsorção nas fases sólidas foram realizados em colunas tipo seringas de plástico empacotadas com as fases sólidas retidas entre duas membranas filtrantes (frit) de polietileno. A quantidade de adsorvente usado nestes cartuchos foi de $150 \mathrm{mg}$. Foram preparados cartuchos de extração para análise das amostras e dos brancos. Na etapa de condicionamento, foram utilizados $5,0 \mathrm{~mL}$ de metanol seguido de $25 \mathrm{~mL}$ de água. 
A retenção dos analitos foi realizada mediante a percolação (vazão inferior a $2 \mathrm{~mL} \mathrm{~min}^{-1}$ ) de $100 \mathrm{~mL}$ das respectivas soluções padrões aquosas na concentração de $10 \mu \mathrm{g} \mathrm{L}^{-1}$. Pela passagem da solução aquosa pelas fases sólidas, obtêm-se as amostras denominadas eluatos. Na etapa de eluição dos analitos retidos na fase sólida, utilizaram-se os solventes e/ou misturas de solventes (eluentes). Os extratos assim obtidos são denominados de eluídos. Para cada fase sólida foi previamente realizado um branco para garantir a qualidade dos adsorventes empregados.

Várias composições de solventes e/ou misturas de solventes foram utilizadas na etapa de eluição. Para TC, utilizou-se, $\mathrm{MeOH} \mathrm{100 \% ,}$ ACN 100\%, solvente de diluição, MeOH:solvente de diluição 50\% (50:50 (v/v)) e ACN: solvente de diluição 50\% (50:50 (v/v)). Para SMX e TM utilizou-se, MeOH 100\%, MeOH 50\%, ACN 100\%, ACN 50\% e fase móvel ( $\mathrm{H}_{2} \mathrm{O}: \mathrm{ACN}: \mathrm{TEA} 799: 200: 1(\mathrm{v} / \mathrm{v}) \mathrm{pH}: 5,9 \pm$ 0,1 corrigido com ácido acético).

\section{Determinação do volume de quebra}

O volume de quebra, definido como o volume de amostra que pode ser percolado através da fase sólida sem perda dos analitos de interesse por lixiviação destes devido ao solvente da própria amostra, ${ }^{22}$ foi determinado com soluções aquosas de água ultrapura, água potável e água do Arroio Dilúvio, fortificadas com os antimicrobianos. As amostras do Arroio Dilúvio foram coletadas antes do recebimento de descargas de efluentes domésticos e hospitalares e fortificadas com os antimicrobianos. As concentrações das soluções utilizadas nestes experimentos foram de $10 ; 5 ; 2,5$ e 1,25 $\mathrm{gg} \mathrm{L}^{-1}$ para TC e 8, 4, 2 e 1 $\mu \mathrm{g} \mathrm{L}^{-1}$ para SMX e TM. Estas soluções foram percoladas pelas colunas contendo aproximadamente $150 \mathrm{mg}$ de cada fase sólida. Dessa forma, a determinação do volume de quebra foi realizada mantendo-se constante a massa do analito, variando-se o volume de solvente, no caso água (25; 50; 100 e $200 \mathrm{~mL})$. A eluição foi realizada com 5,0 $\mathrm{mL}$ de solvente ou mistura de solvente, dependendo dos analitos.

\section{Avaliação dos parâmetros de desempenho dos métodos de quantificação e da extração em fase sólida dos antimicrobianos}

Os parâmetros de desempenho foram seguidos de acordo com o Guia da International Conference on Harmonisaton (ICH), ${ }^{28}$ Agência Nacional de Vigilânica Sanitária (ANVISA) ${ }^{29}$ e INMETRO. ${ }^{3} \mathrm{~A}$ seletividade foi avaliada pela análise das soluções dos brancos dos eluentes obtidos nos estudos de adsorção/dessorção das fases sólidas. As soluções dos brancos foram preparadas utilizando somente as etapas de condicionamento e de adição do solvente de eluição no estudo de adsorção/dessorção. Como critério de aceitação da seletividade determinou-se que os cromatogramas obtidos a partir das soluções dos brancos dos eluentes das fases sólidas não deveriam apresentar bandas cromatograficas na região dos mesmos.

O limite de detecção instrumental (LDI) foi determinado pelo método visual dos cromatogramas obtidos das soluções de concentrações conhecidas e decrescentes preparadas a partir das soluções padrão, até o menor nível detectado. Durante o preparo e análise das soluções, teve-se o cuidado de mantê-las ao abrigo da luz, em um período máximo de 1 dia. Utilizou-se a relação sinal/ruído de 3 como LDI.

O limite de detecção do método (LDM) foi determinado pela análise de soluções dos analitos em estudo nas matrizes a serem analisadas. Cada uma destas soluções passou pela etapa de préconcentração e análise por CLAE-UV. A estimativa do limite de detecção do método foi feita com base na relação sinal-ruído (3 vezes o ruído da linha de base $)^{28,30}$ das bandas cromatográficas geradas nos respectivos cromatogramas.

O limite de quantificação instrumental (LQI) foi calculado multiplicando-se o LDI por 3,33 (LQ = 10 vezes a relação sinal/ruído).

O limite de quantificação do método (LQM) foi determinado como sendo a concentração que produziu uma relação sinal-ruído de 10 vezes nos cromatogramas de cada analito, analisado seguindo o mesmo procedimento analítico do LDM.

A linearidade das curvas analíticas foi determinada com um mínimo de cinco pontos, nas concentrações de 10, 25, 50, 100, 200 $\mu \mathrm{g} \mathrm{L} \mathrm{L}^{-1}$ para TC e 5, 10, 25, 50, $100 \mu \mathrm{g} \mathrm{L}^{-1}$ para SMX e TM, com coeficiente de variação inferior a $2 \%$ para injeções replicadas $(n=$ 3 injeções) a cada nível de concentração, utilizando a padronização externa. Utilizaram-se as soluções padrão de trabalho de TC e as de SMX e TM para determinar a linearidade das respectivas metodologias. As curvas foram determinadas em cada estudo de adsorção/ dessorção e foram expressas pelas equações das retas e coeficiente de correlação (r). Para avaliar a qualidade dessas curvas, verificou-se a estimativa da incerteza devido à função calibração, com os testes de linearidade, de validade de regressão e de eficiência da regressão. ${ }^{31}$ Os resultados destes testes foram tratados por métodos estatísticos através do software Microsoft Excel ${ }^{\circledR}$. Como critério de aceitação da curva analítica, o valor mínimo aceitável do coeficiente de correlação (r) deve ser igual a $0,99 .{ }^{29}$ Para verificar se a equação de regressão é valida no teste para verificação de ajuste do modelo linear e na validade da regressão ${ }^{31}$ não devem ser evidenciadas diferenças estatisticamente significativas, quando avaliadas por análise de variância (ANOVA), ou seja, F calculado deve ser menor que F tabelado, num intervalo de $95 \%$ de confiança.

O intervalo dinâmico da curva analítica foi derivado do estudo de linearidade. Foi estabelecido pela confirmação de que o método apresenta exatidão, precisão e linearidade adequadas quando aplicadas às amostras contendo quantidades de substância dentro do intervalo especificado.

A repetibilidade do método de extração em fase sólida foi verificada pela análise de 3 amostras na concentração do volume de quebra das soluções aquosas de água potável e da água do arroio e percoladas em três cartuchos, de acordo com as etapas do procedimento da pré-concentração/extração. Cada um dos três eluídos foi analisado três vezes ou o suficiente para se obter um coeficiente de variação máximo em função da concentração do analito. 32

De acordo com as normas do ICH $2005,{ }^{28}$ a exatidão foi inferida após a determinação experimental da linearidade, do intervalo dinâmico, da precisão do método e da especificidade do mesmo. A precisão intermediária e a reprodutibilidade neste estudo não foram avaliadas.

\section{RESULTADOS E DISCUSSÃO}

\section{Perfil cromatográfico dos métodos de quantificação dos antimicrobianos}

A avaliação do perfil cromatográfico foi realizada com base nas recomendações da $\mathrm{USP}^{27}$ e FDA. ${ }^{33}$ De acordo com a literatura, ${ }^{34}$ pelo menos dois critérios de avaliação devem ser considerados para demonstrar que o sistema é capaz de fornecer dados confiáveis. Para a TC os dois critérios de avaliação utilizados foram a repetibilidade das áreas e o fator cauda (determinado por 5 análises consecutivas de uma solução padrão de $100 \mu \mathrm{g} \mathrm{L}^{-1}$ ). O coeficiente de variação para a repetibilidade das áreas foi de 1,9\% e o fator de cauda foi de 1,2. Para SMX e TM, os dois critérios utilizados foram a repetibilidade nas áreas (determinado por 5 análises consecutivas de uma solução padrão de $250 \mu \mathrm{g} \mathrm{L}^{-1}$ ) e a resolução entre as bandas cromatográficas. Neste caso, o coeficiente de variação foi de $0,9 \%$ para TM e 3,4\% para SMX e a resolução entre a banda cromatográfica da TM e SMX foi de 14,5 o que é considerado aceitável pela farmacopeia americana. ${ }^{27}$ 


\section{Parâmetros de desempenho do método cromatográfico}

\section{Tetraciclina}

A seletividade foi confirmada pela análise cromatográfica das soluções dos brancos dos eluentes $\mathrm{MeOH}, \mathrm{ACN}$ e solvente de diluição utilizando-se as sílicas modificadas como fase sólida para a etapa de pré-concentração. Os brancos dos eluentes nas fases sólidas em estudo não apresentaram bandas cromatográficas de interferentes próximos ao tempo de retenção da TC. Portanto, eles foram considerados em condições de serem utilizados no sistema de adsorção/dessorção da TC (Figura 1A-1).
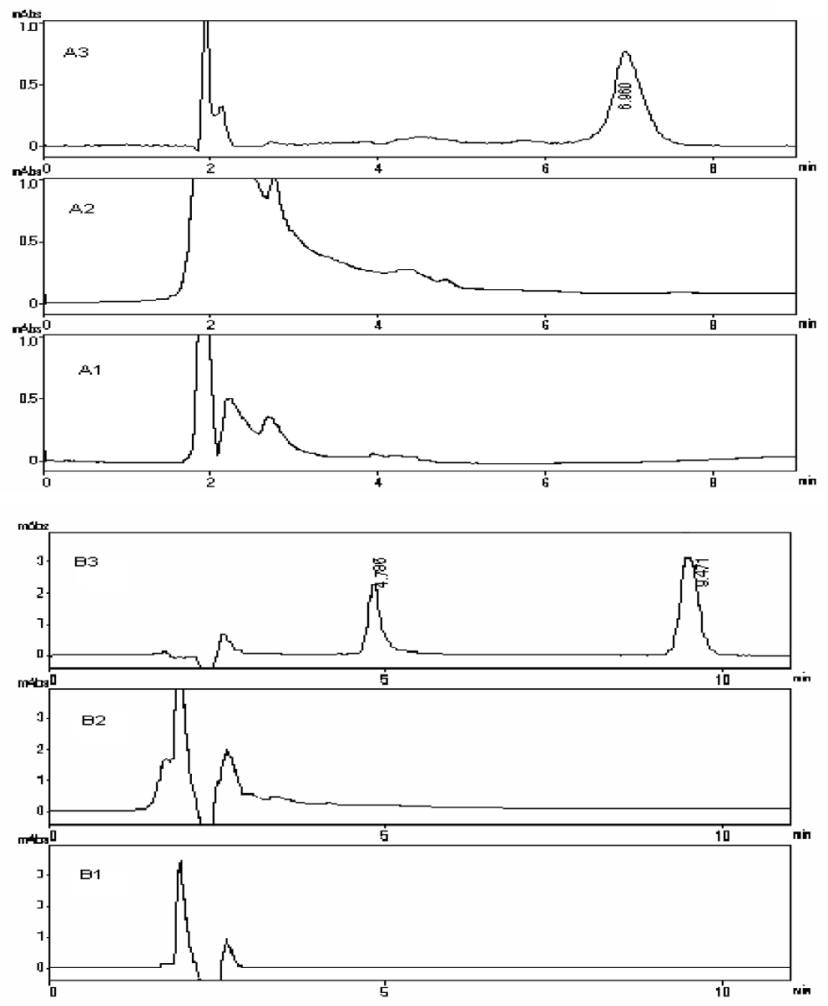

Figura 1. Cromatogramas representativos dos sistemas analisados: (A3) solução padrão de TC na concentração de $500 \mu \mathrm{g}^{-1}$; (A 2) Amostra real para TC na água do arroio Dilúvio; (A1) Branco do solvente de diluição na sílica B para metodologia TC; (B3) solução padrão de SMX e TM $1000 \mu \mathrm{g} L^{-1}$; (B 2) Amostra real para SMX e TM na água do arroio Dilúvio; (B1) Branco do MeOH 50\% na sílica C18 para metodologia de SMX e TM

O limite de detecção instrumental (LDI) para a solução de TC, no solvente de diluição foi de $2,5 \mu \mathrm{g} \mathrm{\textrm {L } ^ { - 1 }}$ e o limite de quantificação instrumental (LQI) foi de $8,32 \mu \mathrm{g} \mathrm{L}^{-1}$.

As curvas analíticas utilizadas nos estudo de adsorção/dessorção apresentaram baixa dispersão no conjunto de pontos experimentais e menor incerteza dos coeficientes de regressão estimados nos intervalos que variaram de 10 a $1000 \mu \mathrm{g} \mathrm{L}^{-1}$. Para a aceitação da linearidade das curvas, considerou-se $F_{\text {cal }} \leq F_{\text {tab }}$, para a regressão $F_{\text {cal }} \geq F_{\text {tab }}$ e $R^{2}$ $>0,95$. Todas as curvas foram aceitas dentro destes critérios, no intervalo de concentração indicado, evidenciando que não houve diferenças estatisticamente significativas quando avaliadas por análise de variância (ANOVA) fator único num intervalo de $95 \%$ de confiança. ${ }^{31}$

\section{Sulfametoxazol e trimetoprima}

A seletividade foi confirmada pela análise cromatográfica das soluções dos brancos dos eluentes $\mathrm{MeOH} 100 \%, \mathrm{MeOH} 50 \%$, ACN $100 \%$, ACN 50\% e fase móvel $\left(\mathrm{H}_{2} \mathrm{O}: \mathrm{ACN}\right.$ :TEA 799:200:1 (v/v)
pH: 5,9 \pm 0,1 corrigido com ácido acético), utilizando-se as sílicas modificadas como fase sólida para a etapa de pré-concentração, não apresentaram bandas cromatográficas de interferentes próximos ao tempo de retenção da SMX e da TM, confirmando a seletividade do método.

O limite de detecção instrumental (LDI) foi de $2,5 \mu \mathrm{g} \mathrm{L} \mathrm{L}^{-1}$ para a solução padrão de SMX e TM dissolvida na fase móvel. O limite de quantificação instrumental (LQI) foi $8,3 \mu \mathrm{g} \mathrm{L}^{-1}$.

As curvas apresentaram baixa dispersão no conjunto de pontos experimentais e menor incerteza dos coeficientes de regressão estimados. O intervalo das curvas foi de 5 a $1000 \mu \mathrm{g} \mathrm{L}^{-1}$. Para a aceitação da linearidade das curvas, considerou-se $\mathrm{F}_{\text {cal }} \leq \mathrm{F}_{\text {tab }}$, para a regressão $F_{\text {cal }} \geq F_{\text {tab }}$ e $R^{2}>0,95$. Todas as curvas foram aceitas dentro destes critérios, no intervalo de concentração indicado.

\section{Estudo de adsorção/dessorção das fases sólidas frente aos antimicrobianos}

\section{Tetraciclina}

Os resultados de recuperação para os antibióticos estudados são apresentados na Tabela 2. Quando da utilização das misturas de solventes (metanol com solvente de diluição (50:50) e acetonitrila com solvente de diluição (50:50)) se observou a formação de um precipitado, não sendo possível a determinação da recuperação. Quando a detecção foi possível, os percentuais de recuperação de TC nos eluídos e eluatos foram determinados pelas curvas analíticas. Os percentuais de recuperação da TC no eluído utilizando metanol e acetonitrila na etapa de eluição, nas diferentes fases sólidas, ficaram abaixo do limite de detecção, pois não foi detectado pico no tempo de retenção característico da TC.

Os percentuais de TC determinados nos eluatos (solução aquosa após a percolação na fase sólida) mostraram a presença de TC apenas para o sistema em que se utilizou a sílica comercial (em torno de $25 \%$ ). Este resultado indica que em torno de $25 \%$ da TC contida na solução não ficou retida na FS, mostrando a baixa seletividade na retenção para este analito (Tabela 2).

Com relação aos eluentes utilizados, o "solvente de diluição" foi o mais eficiente para a dessorção da TC retida nas quatro fases sólidas avaliadas. O solvente de diluição é um sistema que contém oxalato de sódio. A literatura tem registrado que o oxalato previne a formação de quelatos da TC com íons metálicos. ${ }^{14}$ Portanto, a possível formação destes quelatos da TC com o íon metálico das fases sólidas contendo $\mathrm{Zr}$ é contornada, pois o oxalato compete com a TC complexando com estes centros metálicos dessorvendo, assim, a TC inicialmente retida nestas FSs. Reforçando esta hipótese, artigos de cromatografia em camada delgada em fase reversa registram que a TC apresenta marcas de cauda nas placas quando soluções de metanol e acetonitrila são utilizadas como solvente e que soluções contendo ácido oxálico controlam este comportamento, reduzindo as caudas. ${ }^{14}$

A sílica B apresentou a maior recuperação (em torno de 72\%) e a sílica C, a menor (em torno de 56\%). A maior recuperação da TC com as FSs de sílica funcionalizadas com zirconocenos pode ser atribuída também ao fato de que as fases sólidas apresentam grupos silanois residuais na superfície da sílica. De acordo com resultados anteriores ${ }^{23}$ essas fases apresentam em torno de $0,3 \%$ de $\mathrm{Zr} / \mathrm{SiO}_{2}$ e o nível de saturação indica que o conteúdo desse metal é atingido não simplesmente porque a superfície encontra seu nível de saturação (inexistência de grupos silanois para imobilização), mas por efeito estérico desempenhado por zirconocenos imobilizados na superfície, que impedem o acesso de outras moléculas presentes na solução aos grupos silanois residuais. Tendo em vista a presença de grupos silanois residuais na superfície da sílica e a presença de grupos $\mathrm{OH}$ na própria estrutura da TC, pode-se inferir que este 
Tabela 2. Percentual de recuperação de TC, SMX e TM nos eluídos e eluatos nas diferentes fases sólidas

\begin{tabular}{|c|c|c|c|c|c|c|c|c|c|c|c|}
\hline \multirow{3}{*}{$\begin{array}{l}\text { Solventes } \\
\text { FS }\end{array}$} & \multirow[b]{3}{*}{ Fármaco } & \multicolumn{10}{|c|}{ Recuperação (CV \%) } \\
\hline & & \multicolumn{2}{|c|}{$\mathrm{MeOH} 100 \%$} & \multicolumn{2}{|c|}{ ACN $100 \%$} & \multicolumn{2}{|c|}{$\mathrm{MeOH} \mathrm{50 \%}$} & \multicolumn{2}{|c|}{ ACN $50 \%$} & \multicolumn{2}{|c|}{$\mathrm{FM}^{*}$ ou $\mathrm{SD}^{* *}$} \\
\hline & & Eluato & Eluído & Eluato & Eluído & Eluato & Eluído & Eluato & Eluído & Eluato & Eluído \\
\hline \multirow{3}{*}{ Sílica C18 } & $\mathrm{TC}$ & n.d. & n.d. & n.d. & n.d. & $\mathrm{ppt}^{* * * *}$ & $\mathrm{ppt}^{* * *}$ & $\mathrm{ppt}^{* * *}$ & $\mathrm{ppt}^{* * * *}$ & $24(25)$ & $52,0(14)$ \\
\hline & SMX & 0 & 0 & 0 & 0 & 13 & 68 & 51 & 52 & 58 & 39 \\
\hline & TM & 0 & 95 & 0 & 0 & 0 & 95 & 0 & 79 & 0 & 101 \\
\hline \multirow{3}{*}{ Sílica A } & $\mathrm{TC}$ & n.d. & n.d. & n.d. & n.d. & $\mathrm{ppt}^{* * *}$ & $\mathrm{ppt}^{* * *}$ & $\mathrm{ppt}^{* * *}$ & $\operatorname{ppt}^{* * *}$ & n.d. & $68,5(1)$ \\
\hline & SMX & 85 & 0 & $84,5(2)$ & 0 & $89,5(4)$ & $11,5(68)$ & $96(9)$ & $4,5(47)$ & 102 & 5 \\
\hline & TM & 0 & 71 & 0 & 0 & 0 & $15,5(23)$ & 0 & $26,5(83)$ & 0 & 84 \\
\hline \multirow{3}{*}{ Sílica B } & $\mathrm{TC}$ & n.d. & n.d. & n.d. & n.d. & $\mathrm{ppt}^{* * *}$ & $\mathrm{ppt}^{* * *}$ & $\mathrm{ppt}^{* * *}$ & $\mathrm{ppt}^{* * * *}$ & n.d. & $72,5(1)$ \\
\hline & SMX & $94,5(8)$ & 0 & $90,5(10)$ & 0 & $83,5(4)$ & $23,3(22)$ & $98(4)$ & $10,5(68)$ & $93(0)$ & $9,3(63)$ \\
\hline & $\mathrm{TM}$ & 0 & 51 & 0 & 0 & 0 & $42,3(21)$ & 0 & $16,3(78)$ & 0 & $86(7)$ \\
\hline \multirow{3}{*}{ Sílica C } & $\mathrm{TC}$ & n.d. & n.d. & n.d. & n.d. & $\mathrm{ppt}^{* * *}$ & $\mathrm{ppt}^{* * *}$ & $\mathrm{ppt}^{* * *}$ & $\mathrm{ppt}^{* * *}$ & n.d. & $56,7(6)$ \\
\hline & SMX & $98(11)$ & 0 & 95,5 (2) & 0 & $63(4)$ & $20(67)$ & $93,5(5)$ & $19(54)$ & $91(12)$ & $11(57)$ \\
\hline & TM & 0 & 63 & 0 & 0 & 0 & $58(17)$ & 0 & $32(16)$ & 0 & $92,3(10)$ \\
\hline
\end{tabular}

FS - Fase Sólida; n.d. não detectado; *FM - Fase Móvel (água:acetonitrila:trietilamina na proporção de 79,9:20:0,1),); **SD- solvente de diluição (mistura de $680 \mathrm{~mL}$ de oxalato de amônio $0,1 \mathrm{~mol} \mathrm{~L}^{-1} ; 270 \mathrm{~mL}$ de N,N-dimetilformamida); ***houve formação de precipitado

analito possui maior tendência a interagir com fases funcionalizadas com zirconoceno. Além disso, a presença de sítios de ácidos de Lewis sobre os centros de $\mathrm{Zr}$ deve fornecer sítios suplementares para a interação com compostos carboniladoA partir destes dados, a sílica B foi considerada satisfatória para avaliar os parâmetros de validação na metodologia para determinação de TC em matrizes ambientais aquosas.

\section{Sulfametoxazol e trimetoprima}

As recuperações de SMX e TM são apresentadas na Tabela 2. A TM, não foi detectada nos eluatos, o que constitui indicativos de que ela pode ter sido irreversivelmente retida nestas FSs. Por outro lado, os percentuais de SMX nos eluatos indicam que a mesma foi pouco retida nas FSs, (63 a 102\% presente nos eluatos), exceto na sílica comercial.

A fase móvel, composta por água:acetonitrila:trietilamina (79,9:20:0,1), com uma maior proporção de solvente polar (água) e com um reagente de pareamento iônico (trietilamina) na sua composição, apresentou valores de recuperação maiores para TM (de 84 a $101 \%$ ) nas quatro FSs. O objetivo da trietilamina na fase móvel é diminuir o efeito dos grupos silanois residuais eventualmente presentes na coluna analítica ou nas fases à base de sílica. Este reagente aniônico confere carga negativa adicional à FS, reduzindo a retenção da amostra por troca iônica com os grupos silanois. ${ }^{34}$

Nas sílicas funcionalizadas com metalocenos, infere-se que a interação com a superfície da sílica pode se dar tanto pelos grupos silanois residuais através de ligações de hidrogênio, como pela formação de um par base/ácido de Lewis (respectivamente, nitrogênio dos fármacos e centro metálico, $\mathrm{Zr}$ ) que expande sua esfera de coordenação. Resultados semelhantes encontram-se descritos na literatura para sistemas análogos (por exemplo, Costa et al.). ${ }^{35}$

\section{Volume de quebra em água ultrapura, água potável e água do arroio Dilúvio}

\section{Tetraciclina}

A Figura 2 mostra o gráfico do volume de quebra da solução aquosa de TC em água ultrapura, água potável e água do arroio Dilúvio para a sílica $\mathrm{B}$, utilizando solvente de diluição como eluente.

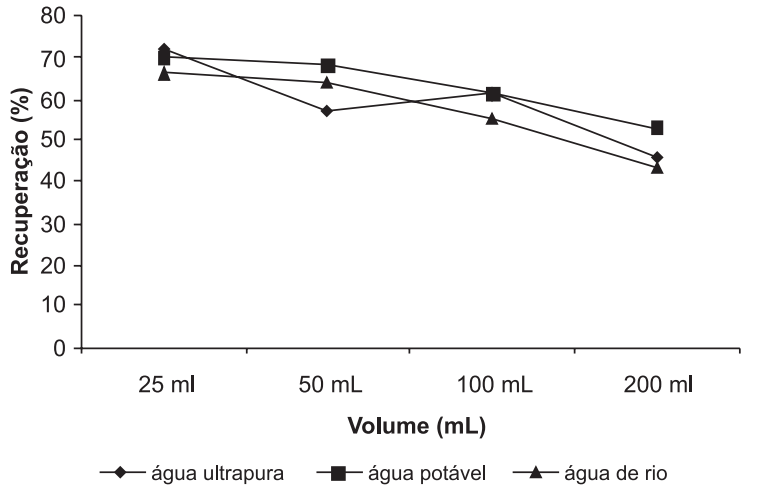

Figura 2. Volume de quebra da solução de TC em água ultrapura, água potável e água do arroio Dilúvio para a sílica a $200^{\circ} \mathrm{C}$

Observa-se que o perfil gráfico do volume de quebra em águas ultrapura, potável e do arroio foi semelhante, ou seja, entre 25 e 50 $\mathrm{mL}$ têm-se os valores máximos de recuperação. No entanto, na água do arroio, a recuperação apresentou redução em torno de $60 \%$, quando comparada com os valores obtidos para águas ultrapura e potável. Esta redução na recuperação pode ser justificada devido à presença de ácidos húmicos e fúlvicos, que podem competir com os analitos pelos sítios adsorventes da fase sólida e levar a uma redução na recuperação da TC.

Considerando o volume de quebra de $25 \mathrm{~mL}$ e volume final do extrato de $5 \mathrm{~mL}$, temos um fator de concentração de 5 . Este comportamento era esperado, pois para compostos moderadamente polares, segundo a literatura, recuperações quantitativas, dependendo do analito em questão, são encontradas na faixa de volume de quebra de 10 a $100 \mathrm{~mL} .{ }^{36}$

\section{Sulfametoxazol e trimetoprima}

A Figura 3 mostra o gráfico do volume de quebra da SMX em água ultrapura, água da torneira e água do arroio Dilúvio na sílica comercial C18 Waters, utilizando como eluente metanol:água (50:50).

Observa-se que para a SMX há uma constante redução na recuperação, à medida que o volume de água aumenta.

$\mathrm{Na}$ Figura 4, tem-se o volume de quebra para a TM, nas mesmas matrizes. Observa-se pequena variação na faixa de 40 a $60 \%$, sem decréscimo significativo na faixa de volume de solução considerada. 


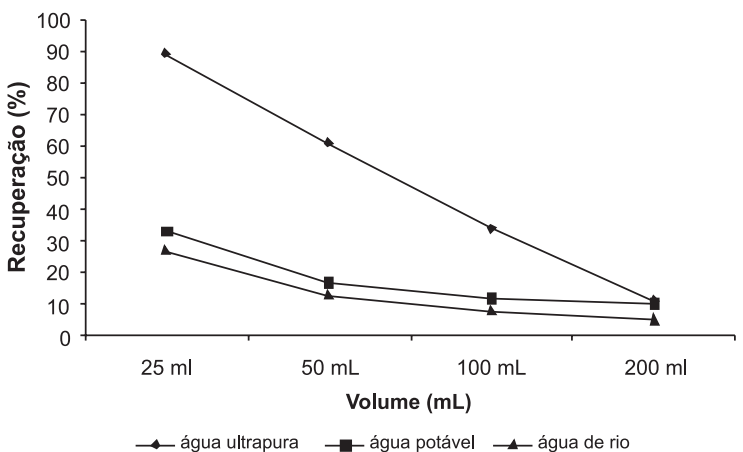

Figura 3. Volume de quebra da solução de sulfametoxazol em água ultrapura, água potável e água do arroio Dilúvio para a sílica comercial

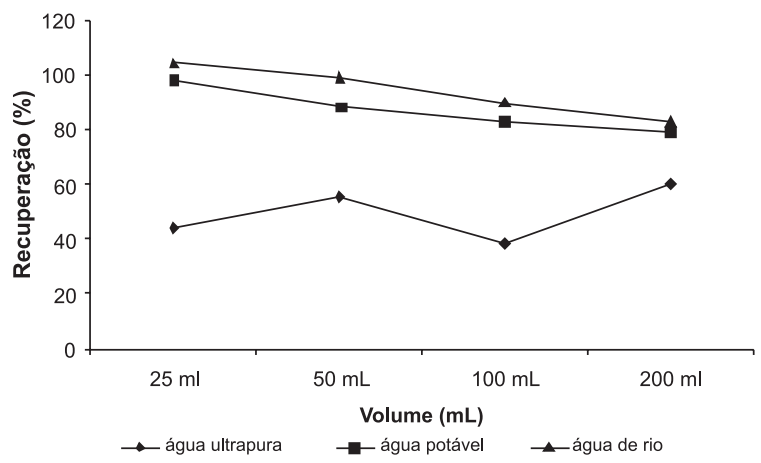

Figura 4. Volume de quebra da solução de trimetoprima em água ultrapura, água potável e água do arroio Dilúvio para a sílica comercial

De acordo com as determinações de volume de quebra em águas ultrapura e potável, realizados em duplicata, a SMX teve um comportamento mais homogêneo quando comparado à TM. Pode-se dizer então que a TM é mais sensível à técnica de análise ou que a técnica não é robusta para analisar TM. Este aspecto pode estar ligado às variações de lotes de fabricação da sílica comercial durante o estudo.

De acordo com os resultados, o comportamento dos volumes de quebra nas águas potável e do arroio é semelhante e segue a tendência do perfil de curva de volume de quebra padrão. Estes gráficos mostram queda nas recuperações de SMX quando comparado à água ultrapura, que pode ser justificada pelo aumento da complexidade da matriz.

A partir destes resultados, o volume de $25 \mathrm{~mL}$ foi escolhido, pois apesar de influenciar pouco a TM, há perda considerável para a SMX, quando o volume é maior que este. Considerando-se que o volume final do extrato é de $5 \mathrm{~mL}$, o fator de concentração é 5 .

\section{Parâmetros de desempenho para a extração em fase sólida na matriz de água do arroio Dilúvio, na água potável e na água ultrapura na determinação dos antimicrobianos}

\section{Tetraciclina}

As curvas analíticas, utilizadas nesta etapa, apresentaram baixa dispersão no conjunto de pontos experimentais e menor incerteza dos coeficientes de regressão estimados nos intervalos de 25-100 $\mu \mathrm{g} \mathrm{L}^{-1}$ em água potável e 12,5-200 $\mu \mathrm{g} \mathrm{L}^{-1}$ na água do arroio Dilúvio.

O limite de detecção do método na água ultrapura foi de 4,6 $\mu \mathrm{g}$ $\mathrm{L}^{-1}$ na amostra pré-concentrada e de $0,9 \mu \mathrm{g} \mathrm{L}^{-1}$ na amostra e o limite de quantificação do método foi de $15 \mu \mathrm{g} \mathrm{L}^{-1}$ na amostra pré-concentrada e de $3 \mu \mathrm{g} \mathrm{L}{ }^{-1}$ na amostra.

A Tabela 3 resume os dados de recuperação em $25 \mathrm{~mL}$ de água potável e do arroio Dilúvio fortificadas com $0,25 \mu \mathrm{g}$ de TC, a repetibilidade, o LDM e o LQM na metodologia em estudo.
Tabela 3. Precisão, LDM e LQM da TC, SMX e TM em água potável e da água do arroio

\begin{tabular}{|c|c|c|c|c|c|}
\hline Matriz & & $\begin{array}{l}\text { Recuperação } \\
(\%) \pm \mathrm{DP}\end{array}$ & $\begin{array}{l}\text { Repetibilidade } \\
\text { (CV\%) }\end{array}$ & $\begin{array}{l}\mathrm{LDM} \\
\left(\mu \mathrm{g} \mathrm{L}^{-1}\right)\end{array}$ & $\begin{array}{l}\text { LQM } \\
\left(\mu \mathrm{g} \mathrm{L}^{-1}\right)\end{array}$ \\
\hline \multirow{3}{*}{$\begin{array}{l}\text { Água } \\
\text { potável }\end{array}$} & $\mathrm{TC}$ & $48,9 \pm 2,5$ & 5,2 & $\begin{array}{c}5,1^{*} \\
1,0^{* *}\end{array}$ & $\begin{array}{l}17,0^{*} \\
3,4^{* *}\end{array}$ \\
\hline & SMX & $33,0 \pm 0,4$ & 1,3 & $\begin{array}{c}4,8^{*} \\
1,0^{* *}\end{array}$ & $\begin{array}{l}16,0^{*} \\
3,2^{* *}\end{array}$ \\
\hline & $\mathrm{TM}$ & $98,3 \pm 4,6$ & 4,7 & $\begin{array}{c}5,7^{*} \\
1,1^{* *}\end{array}$ & $\begin{array}{l}19,0^{*} \\
3,8^{* *}\end{array}$ \\
\hline \multirow{3}{*}{$\begin{array}{l}\text { Água do } \\
\text { Arroio } \\
\text { Dilúvio }\end{array}$} & TC & $66,3 \pm 3,6$ & 5,5 & $\begin{array}{l}18,0^{*} \\
3,6^{* *}\end{array}$ & $\begin{array}{c}60,0^{*} \\
12,0^{* *}\end{array}$ \\
\hline & SMX & $27,3 \pm 2$ & 8,7 & $\begin{array}{l}1,6^{*} \\
0,3^{* *}\end{array}$ & $\begin{array}{l}5,3^{*} \\
1,1^{* *}\end{array}$ \\
\hline & $\mathrm{TM}$ & $104 \pm 2,3$ & 2,2 & $\begin{array}{l}1,3^{*} \\
0,3^{*}\end{array}$ & $\begin{array}{c}4,3^{*} \\
0,9 * *\end{array}$ \\
\hline
\end{tabular}

Recuperação e desvio padrão (DP) para TC são dados ( $\mathrm{n}=3$ ) no nível de concentração de $10 \mu \mathrm{g} \mathrm{L}^{-1}$. Para SMX e TM a recuperação e desvio padrão (DP) são dados no nível de concentração de $8 \mu \mathrm{g} \mathrm{L} \mathrm{L}^{-1}$; * amostra pré-concentrada; ** na amostra.

A repetibilidade do método de extração em fase sólida e o volume de quebra na água do arroio Dilúvio foram verificados na mesma amostra (Tabela 3).

A exatidão do método foi inferida, pois o método apresentou linearidade nos intervalos propostos, além de precisão e especificidade.

\section{Sulfametoxazol e trimetoprima}

As curvas analíticas para os dois analitos apresentaram baixa dispersão no conjunto de pontos experimentais e menor incerteza dos coeficientes de regressão estimados, no intervalo de 10-200 $\mu \mathrm{g}$ $\mathrm{L}^{-1}$, em águas ultrapura, potável e do arroio.

O limite de detecção do método (LDM), na água ultrapura, foi de $6,1 \mu \mathrm{g} \mathrm{L}^{-1}$ na amostra pré-concentrada e de $1,2 \mu \mathrm{g} \mathrm{L}^{-1}$ na amostra e o limite de quantificação do método (LQM), na água ultrapura, foi de $20 \mu \mathrm{g} \mathrm{L}^{-1}$ na amostra pré-concentrada e de $4 \mu \mathrm{g} \mathrm{L}^{-1}$ na amostra, para os dois analitos.

A Tabela 2 resume a recuperação em $25 \mathrm{~mL}$ de água potável e do arroio fortificadas com $0,2 \mu \mathrm{g} \mathrm{L}^{-1}$ de SMX e TM, o LDM e de LQM na metodologia em estudo.

Semelhante à metodologia da $\mathrm{TC}$, a repetibilidade do método de extração em fase sólida e o volume de quebra na água do Arroio Dilúvio foram verificadas na mesma amostra. No entanto, nas amostras de água potável considerou-se apenas a repetibilidade das injeções referentes ao extrato de $25 \mathrm{~mL}$ da amostra do volume de quebra (Tabela 3).

A exatidão do método foi inferida, pois o método apresentou linearidade nos intervalos propostos, precisão e especificidade.

\section{Determinação dos antimicrobianos em amostras de água do arroio Dilúvio}

Utilizando-se as melhores condições para analisar a amostra real, com a sílica B na extração em fase sólida e obtendo-se um fator de concentração de 5 vezes com o solvente de diluição, não foi detectada banda cromatográfica referente à TC na água do arroio Dilúvio.

A não detecção da TC nas amostras analisadas pode ser tanto pela ausência de traços da mesma, como devido ao seu alto coeficiente de adsorção (Kds), o qual deslocaria a mesma para o material particulado presente nas amostras. A literatura vem registrando estudos sobre a adsorção de fármacos nos solos ${ }^{37-40}$ e a concentração de antimicro- 
bianos nos sedimentos dos leitos dos rios, que podem se tornar mais importantes para antimicrobianos com alto coeficiente de adsorção. Kds é definido como a razão da concentração de um composto na fase sólida (Cs) e na água (Caq), no equilíbrio. A TC tem Kds $=84000$ $\mathrm{mL} \mathrm{g}^{-1},{ }^{38}$ no entanto, a variação de Kds para um dado composto pode ser significante em diferentes solos. ${ }^{40}$ Portanto, a tetraciclina pode ter um potencial risco, e investigações nos efeitos ambientais desse antimicrobiano são necessárias.

Com relação à SMX e TM, não foram detectadas bandas cromatográficas nos tempos de retenção relativos a estes analitos, nas amostras analisadas.

\section{CONCLUSÃO}

As fases sólidas sintetizadas no laboratório apresentaram potencial para a pré-concentração de tetraciclina, sulfametoxazol e trimetoprima a partir de amostras aquosas. Observou-se que a temperatura de ativação da sílica (que determina o grau de substituição dos grupos silanois) tem grande efeito na recuperação destes compostos, tendo-se obtido valores que variaram de 5 a $98 \%$ dependendo da combinação analito/fase sólida/solvente para eluição. Para que fosse possível a determinação simultânea de SMX e TM, utilizou-se a condição que apresentou a melhor recuperação para ambas. A fase sólida que apresentou a melhor recuperação para tetraciclina (72\%) foi a sílica B, utilizando o solvente de diluição como eluente. Para sulfametoxazol e trimetoprima a melhor recuperação foi obtida com fase sólida comercial C18, utilizando metanol:água (50:50) como eluente (68\% para SMX e $95 \%$ para TM). O volume de quebra obtido foi de $25 \mathrm{~mL}$ e o fator de concentração foi de 5 vezes. Os limites de detecção e quantificação do método de análise de tetraciclina em água ambiental foram de 3,6 e 12,0 $\mathrm{g} \mathrm{L} \mathrm{L}^{-1}$, respectivamente. Para o método de análise de sulfametoxazol e trimetoprima os limites foram de 0,3 e $1,1 \mu \mathrm{g} \mathrm{L}^{-1}$, respectivamente, para sulfametoxazol e de 0,3 e $0,9 \mu \mathrm{g}$ $\mathrm{L}^{-1}$, respectivamente, para trimetoprima. No entanto, não é possível inferir se estes valores são satisfatórios em termos ambientais, uma vez que não há legislação especifica. Os parâmetros de validação parcial para ambas as metodologias foram satisfatórios. A análise da amostra real coletada do arroio Dilúvio não apresentou traços de tetraciclina, sulfametoxazol e trimetoprima nas metodologias utilizadas.

\section{MATERIAL SUPLEMENTAR}

Está disponível em http://quimicanova.sbq.org.br, na forma de arquivo PDF, com acesso livre.

\section{REFERÊNCIAS}

1. Tauxe-Wuersch, A.; De Alencastro, L. F.; Grandjean, D.; Tarradellas, J.; Water Res. 2005, 39, 1761.

2. Daughton, C. H.; Ternes, T. A.; Environ. Health Perspec. 2000, 108, 598.

3. Kummerer, K.; J. Environ. Manag. 2009, 90, 2354.

4. Ollers, S.; Singer, H. P.; Fassler, P.; Muller, S. R.; J. Chromatogr., A 2001, 911, 225.

5. La Farre, M.; Ferrer, I.; Ginebreda, A.; Figueras, M.; Olivella, L.; Tirapu, L.; Vilanova, M.; Barcelo, D.; J. Chromatogr., A 2001, 938, 187.

6. Togola, A.; Budzinski, H.; Anal. Bioanal. Chem. 2007, 388, 627.

7. Diaz-Cruz, M. S.; Garcia-Galan, M. J.; Barceló, D.; J. Chromatogr., A 2008, 1193, 50 .
8. Togola, A.; Budzinski, H.; J.Chromatogr., A 2008, 1177, 150.

9. Hirsch, R.; Ternes, T.; Haberer, K.; Kratz, K. L.; Sci. Total Environ. 1999, 225, 109.

10. Zhu, J.; Snow, D. D.; Cassada, D. A.; Monson, S. J.; Spalding, R. F.; J. Chromatogr, A 2001, 928, 177.

11. Zhou, J. K.; Gerhardt, G. C.; Baranski, A.; Cassidy, R.; J. Chromatogr., A 1999, 839, 193.

12. Schenck, F. J.; Callery, P. S.; J. Chromatogr., A 1998, 812, 99.

13. Renew, J. E.; Huang, C. H.; J. Chromatogr., A 2004, 1042, 113.

14. Oka, H.; Ito, Y.; Matsumoto, H.; J. Chromatogr., A 2000, 882, 109.

15. Nozal, L.; Arce, L.; Simonet, B. M.; Rios, A.; Valcarcel, M.; Anal. Chim. Acta 2004, 517, 89.

16. Lindsey, M. E.; Meyer, M.; Thurman, E. M.; Anal. Chem. 2001, 73, 4640 .

17. Hirsch, R.; Ternes, T. A.; Haberer, K.; Mehlich, A.; Ballwanz, F.; Kratz, K. L.; J. Chromatogr., A 1998, 815, 213.

18. Feitosa-Felizzola, J.; Chiron, S.; J. Hydrology 2009, 364, 50.

19. Chen, Y. C.; Lin, C. E.; J. Chromatogr., A 1998, 802, 95.

20. Kummerer, K.; Chemosphere 2009, 75, 417.

21. Queiroz, S. C. N.; Collins, C. H.; Jardim, I.; Quim. Nova 2001, 24, 68.

22. Fritz, J. S. Em Analytical Solid-Phase Extraction; John Wiley \& Sons, Inc: New York, 1999.

23. Geller, A. M.; Disssertação de Mestrado, Universidade Federal do Rio Grande do Sul, Brasil, 2003.

24. Geller, A. M.; Stedile, F. C.; Peralba, M. D. R.; Pizzolato, T. M.; dos Santos, J. H. Z.; J. Colloid Interface Sci. 2006, 299, 163.

25. Geller, A. M.; Stedile, F. C.; Peralba, M. D. R.; Pizzolato, T. M.; dos Santos, J. H. Z.; J. Colloid Interface Sci. 2005, 288, 45.

26. dos Santos, J. H. Z.; Krug, C.; da Rosa, M. B.; Stedile, F. C.; Dupont, J.; Forte, M. D.; J. Mol. Catal. A: Chem. 1999, 139, 199.

27. USP The United States Pharmacopeia; $28^{\text {th }}$ ed.; United States Pharmacopeial Convention: Rockville, 2005.

28. ICH; Validation of Analytical Procedures: Text and Methodology Q2(R1); International Conference on Harmonisation (ICH) of Technical Requirements for Registration of Pharmaceuticals for Human Use, Geneve, 2005.

29. ANVISA; Resolução da Diretoria Colegiada 899, de 29 de maio de 2003 Guia Sanitário, Ministério da Saúde: Brasilia, 2003; http://portal. anvisa.gov.br, acessada em Dezembro 2010.

30. INMETRO - Instituto Nacional de Metrologia, http://www.inmetro.gov. br, acessada em Dezembro 2010.

31. Chui, Q. S. H.; Zucchini, R. R.; Lichtig, J.; Quim. Nova 2001, 24, 374.

32. AOAC Peer Verified Methods Program; Manual on policies and procedures, Arlington, VA, 1993.

33. FDA; Center for Drug Evaluation and Research, Federal Drug Administration: Rockville, 2000.

34. Snyder, L. R.; Kirkland, J. J.; Glajch, J. L.; Practical HPLC Method Development, John Wiley: Nova Iorque, 1997.

35. Vaya, V. I. C.; Belelli, P. G.; dos Santos, J. H. Z.; Ferreira, M. L.; Damiani, D. E.; J. Catal. 2001, 204, 1.

36. Araujo, M. B. C.; Tese de Doutorado, Universidade Federal do Rio Grande do Sul, Brasil, 2004.

37. Hamscher, G.; Sczesny, S.; Hoper, H.; Nau, H.; Anal. Chem. 2002, 74, 1509.

38. Batt, A. L.; Bruce, I. B.; Aga, D. S.; Environ. Pollut. 2006, 142, 295.

39. Kim, S.; Eichhorn, P.; Jensen, J. N.; Weber, A. S.; Aga, D. S.; Environ. Sci. Technol. 2005, 39, 5816.

40. Tolls, J.; Environ. Sci. Technol. 2001, 35, 3397. 


\section{DESENVOLVIMENTO DE MÉTODOS DE ANÁLISE POR CLAE-UV PARA OS ANTIMICROBIANOS TETRACICLINA, SULFAMETOXAZOL E TRIMETOPRIMA UTILIZANDO MATERIAIS À BASE DE SÍLICA COMO SISTEMAS DE PRÉ-CONCENTRAÇÃO}

Rosana Cristina Ribeiro Pedroso, Maria do Carmo Ruaro Peralba, João Henrique Zimnoch dos Santos e Tânia Mara Pizzolato* Instituto de Química, Universidade Federal do Rio Grande do Sul, Av. Bento Gonçalves, 9500, 91501-970 Porto Alegre - RS, Brasil Pedro Eduardo Fröehlich

Faculdade de Farmácia, Universidade Federal do Rio Grande do Sul, Av. Ipiranga, 2752, 90610-000 Porto Alegre - RS, Brasil

(A3)

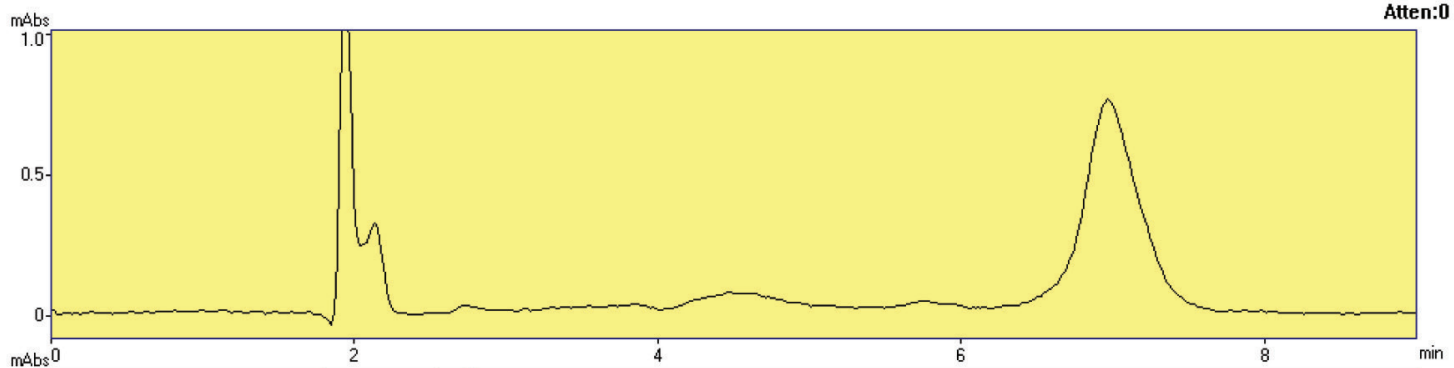

(A2)

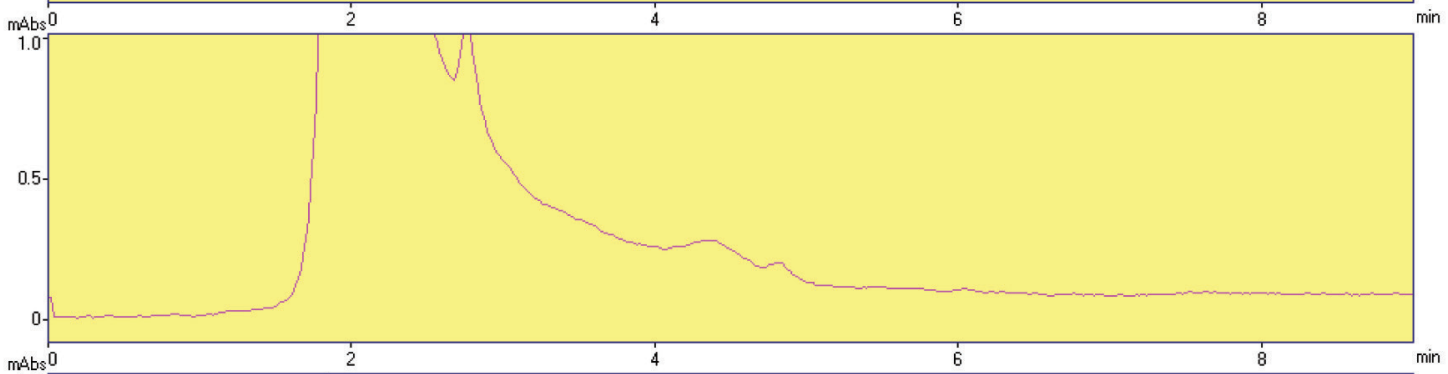

(A1)

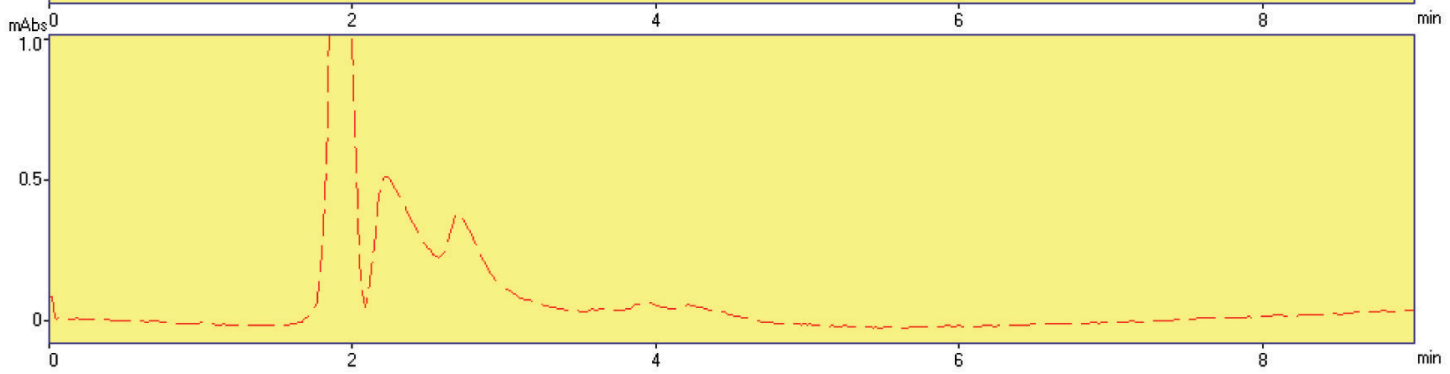

Figura 1. (A1) - Branco do solvente de diluição na sílica B para metodologia TC. (A2) - Amostra real de TC na água do arroio Dilúvio. (A3) - Solução padrão de TC na concentração de $500 \mu g L^{-1}$ 


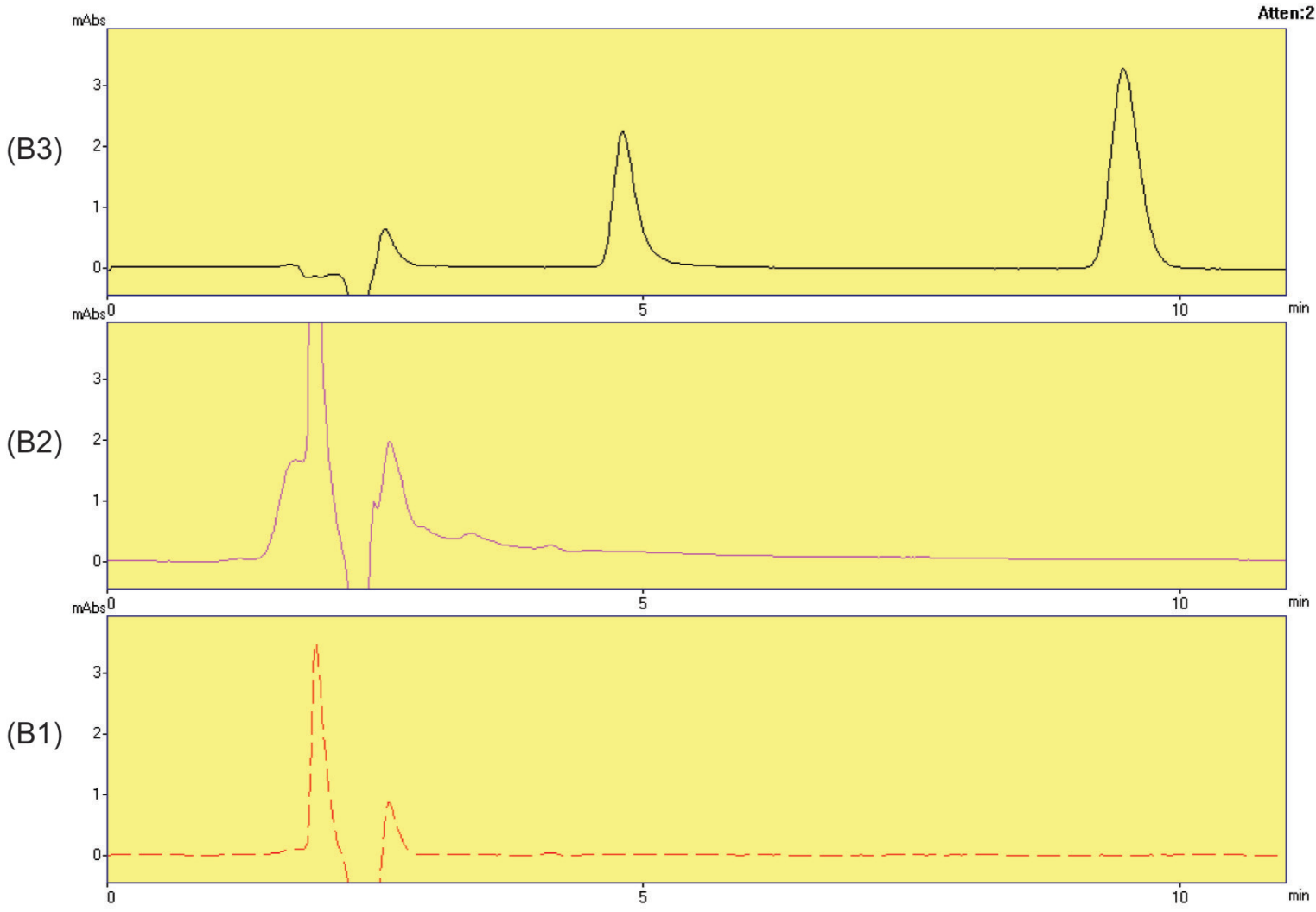

Figura 2. (B1) - Branco do MeOH 50\% na sílica C18 para metodologia de SMX e TM. (B2) - Amostra real de SMX e TM na água do arroio Dilúvio. (B3) Solução padrão de SMX e TM $1000 \mu g L^{-1}$ 